\title{
Experimental Study on the Responses of Bucket Foundations in Calcareous Sand under Vertical Dynamic Loading
}

\author{
Xiaobing $\mathrm{Lu}^{*}{ }^{1}$, Li Wang ${ }^{1}$ and Zhongmin $\mathrm{Shi}^{2}$ \\ ${ }^{1}$ Institute of Mechanics, Chinese Academy of Sciences, Beijing, 100190, China \\ ${ }^{2}$ Research Center, COONC, Beijing, 100027, China
}

\begin{abstract}
Experiments to determine the vertical static bearing capacity are carried out first in laboratory which is taken as a reference for choosing the amplitudes of vertical dynamic loading. Then a series of experiments are carried out to study the influences of factors, such as the scales of bucket, the amplitude and frequency of loading, the density of soils etc.. According to the experimental results, the responses of bucket foundations in calcareous sand under vertical dynamic loadings are analyzed. It is shown that there exists a limited effected zone under vertical dynamic loading. The scale of this zone is about one times of the bucket's height. In this zone, the density of soil layer, the deformation and the pore pressure change obviously.
\end{abstract}

Keywords: Calcareous sand, bucket foundation, vertical dynamic loading.

\section{INTRODUCTION}

A suction bucket foundation is a closed-top steel tube that is lowered to the seafloor, allowed to penetrate the bottom sediments under its own weight first, and then pushed to full depth with suction force produced by pumping water out of the interior. In recent years, suction bucket foundations have been used increasingly often for gravity platform jackets, jack-ups [1-3]. They also have the potential of being used for several other purposes, such as offshore wind turbines, submarine systems and seabed protection structures [4-7].

Despite some studies about the installation and bearing capacity have been studied, the detail responses of the suction bucket foundations under dynamic loads have remained unknown [8-10]. The dynamic load condition is significant when suction buckets are used as the foundation of an offshore structure. Wave load, ice-induced or wind- induced load causes the foundation to be subjected to cyclic loads [11-13].

In the tropic marine area, such as in the zone of South China Sea, the Australia Sea, the calcareous sand is distributed widely. This type of sand has special characteristics: crushing and disintegration at low stresses compared with siliceous particles, macropores and cementation [14].

Several studies on the static and dynamic responses of suction piles and suction caissons in calcareous sand have been undertaken in the last three decades. Angemeer [15] and Khorshid [16] carried out field pile tests in calcareous sand. Randolph et al. [17] studied the static and dynamic responses of suction piles in fine calcareous sand by cen

*Address correspondence to this author at the Institute of Mechanics, Chinese Academy of Sciences, Beijing, 100190, China; Tel: 861082544190; E-mail: xblu@imech.ac.cn trifugal experiments. Dyson and Randolph [18], Riadh and Poulos et al. [19, 20] studied the horizontal static bearing capacity of piles in calcareous sand in north-west shelf of Australia. Watson and Randolph [21] carried out centrifugal experiments to study the vertical bearing capacity of suction caissons under drained and undrained conditions in the calcareous sand in north-west shelf of Australia. Cassidy et al. $[22,23]$ studied the bearing capacity of circular footings in calcareous sand by experiments and numerical modeling. Chu et al. and Shan et al. [24, 25] studied the static bearing capacity of plate anchors in calcareous sand.

In the above viewpoint, aims in this paper are on the dynamic responses of bucket foundations in the calcareous sand under vertical loading. A series of experiments in laboratory are carried out to investigate the effects of factors, such as the amplitude and frequency of loading, the density of sand, the scales of bucket. The characteristics of dynamic responses are also investigated, such as the development of pore pressure and displacements.

\section{INTRODUCTION OF EXPERIMENTAL SETUP}

\section{Experimental Soils}

Loose calcareous sand obtained from Yongshu reef in South China Sea is used in experiments. The coarse grains whose diameters are bigger than $5 \mathrm{~mm}$ are griddled before grain series analysis. The grain series curve is shown in Fig. (1). The relative density of sand is $0.5 \sim 0.6$. The other physical parameters are shown in Table $\mathbf{1}$.

\section{Model Box}

The model box used in experiments has the inner scales of: length $\times$ width $\times$ height $=50 \mathrm{~cm} \times 50 \mathrm{~cm} \times 45 \mathrm{~cm}$. It is made by organic glasses. A steel circular bucket is put vertically in the center of the model box to model the bucket foundation. 


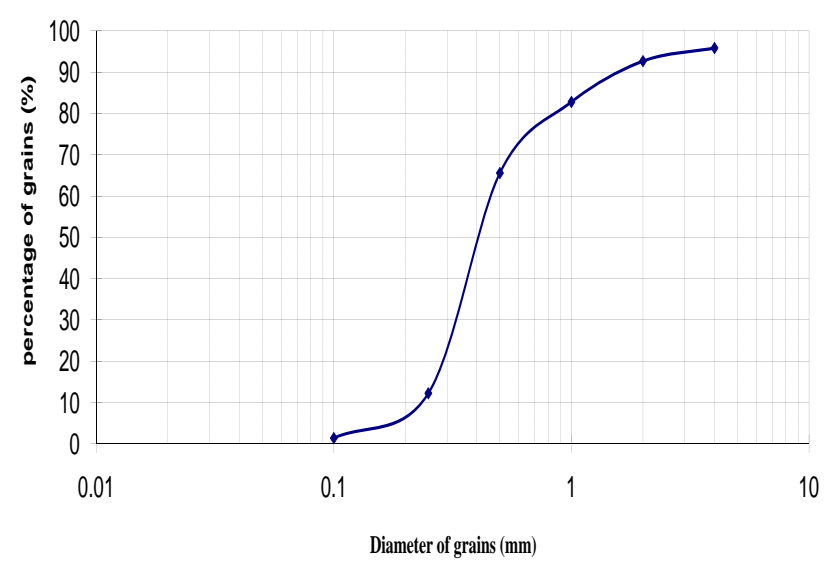

Fig. (1). Grain series curve.

Table 1. Physical Parameters of Calcareous Sand Used in Experiments

\begin{tabular}{|c|c|c|c|c|c|}
\hline $\mathbf{C}$ & $\boldsymbol{\Phi}$ & $\begin{array}{c}\text { Permeability } \\
\mathbf{k}(\mathbf{c m} / \mathbf{s})\end{array}$ & $\begin{array}{c}\text { D10 } \\
(\mathbf{c m})\end{array}$ & $\begin{array}{c}\text { D60 } \\
(\mathbf{c m})\end{array}$ & $\mathbf{D}_{\mathbf{r}}$ \\
\hline \hline 0 & $47.7^{\circ}$ & $5 \times 10^{-2}$ & 0.024 & 0.046 & $\begin{array}{c}0.5- \\
0.6\end{array}$ \\
\hline
\end{tabular}

\section{Electro-Hydraulic Service Loading System}

The layout of loading system is shown in Fig. (2). The loading system may output force with an amplitude of $0 \sim 100 \mathrm{~kg}$ or output displacement with an amplitude of $0 \sim 5 \mathrm{~cm}$. The output frequency is $0.1 \sim 20 \mathrm{~Hz}$. Displacement control mode is used in experiments. The force transducers and pore pressure transducers (PPT) are lay out before the starting of experiments. The counter force of bucket, the displacement of bucket, the pore pressure and vertical displacement of bucket are measured during each experiment.

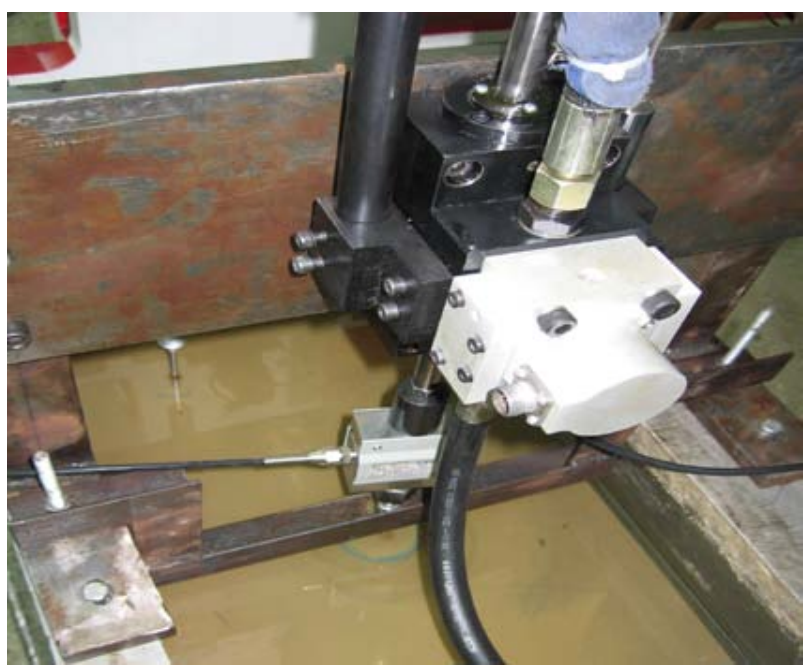

Fig. (2). Sketch of the experimental layout.

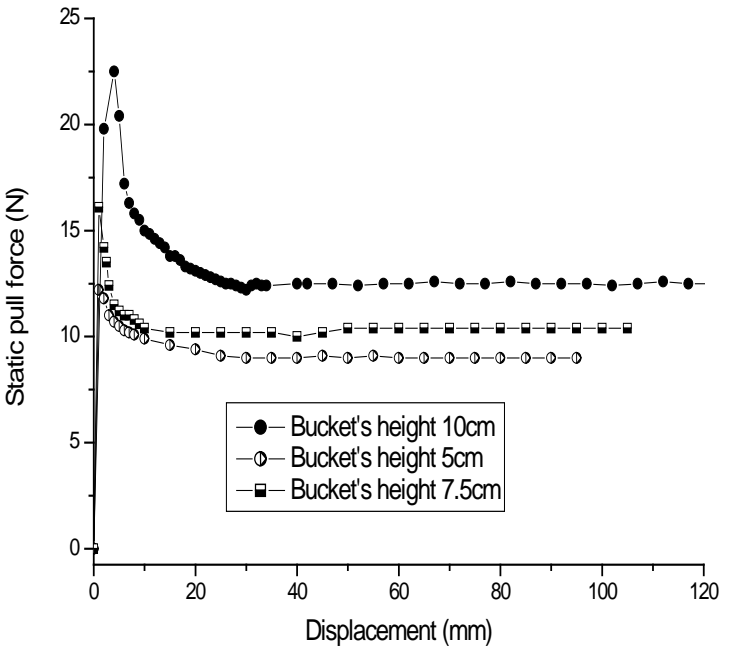

Fig. (3). Curves of vertical static loading-displacement.

\section{The Transducers and Data Acquisition System}

Two force transducers are made by the 701 institute in China and have the measure ranges of $15 \mathrm{~kg}$ and $80 \mathrm{~kg}$, respectively. The PDCR81 type PPTs are made by Druck Co. in English and have a diameter of $0.64 \mathrm{~cm}$ and a length of $1.14 \mathrm{~cm}$. The measure ranges are $14 \mathrm{kPa}, 7.5 \mathrm{kPa}$, respectively. All PPTs were saturated in a vacuum environment and demarcated before each experiment. The data acquisition system (USB2005 16 bit) is made by ALTAI Co. in China, the sampling frequency is $10 \mathrm{kHz}$.

\section{Preparation of Sand Layer and Experimental Steps}

\section{(1) Sand Foundation Preparation}

The sample with a height of $27 \mathrm{~cm}$ high and a dry density of $1.260 \mathrm{~g} / \mathrm{cm}^{3}$ is compacted by 9 layers. The model bucket is pressed into the sample and the PPTs are floated in sand sample. The top of the bucket is at the same level of the sand layer surface. After finishing the preparing of sample, it is saturated by filling water from the bottom of the model box. In order to assure the percolation of water uniform and prevent piping, a layer of fine sand with a thickness of $1.0 \mathrm{~cm}$ is put on the bottom of the model box. There is a layer of permeable cloth over the layer of fine sand. The water pressure method is adopted to saturated the sample because the calcareous sand has a relative big permeability. The saturation degree is over $98 \%$ by measuring the pore pressure. The water surface is $2 \mathrm{~cm}$ over the sand surface after saturation. The sample is lay for 24 hours before loading is applied.

The positions of the PPTs change during experiments, thus the positions are measured after each experiment.

\section{(2) Experimental Steps}

- Prepare sand foundation. Turn on the loading system and check transducers.

- Connect the loading head and the bucket by a gimbal which may move vertically. 

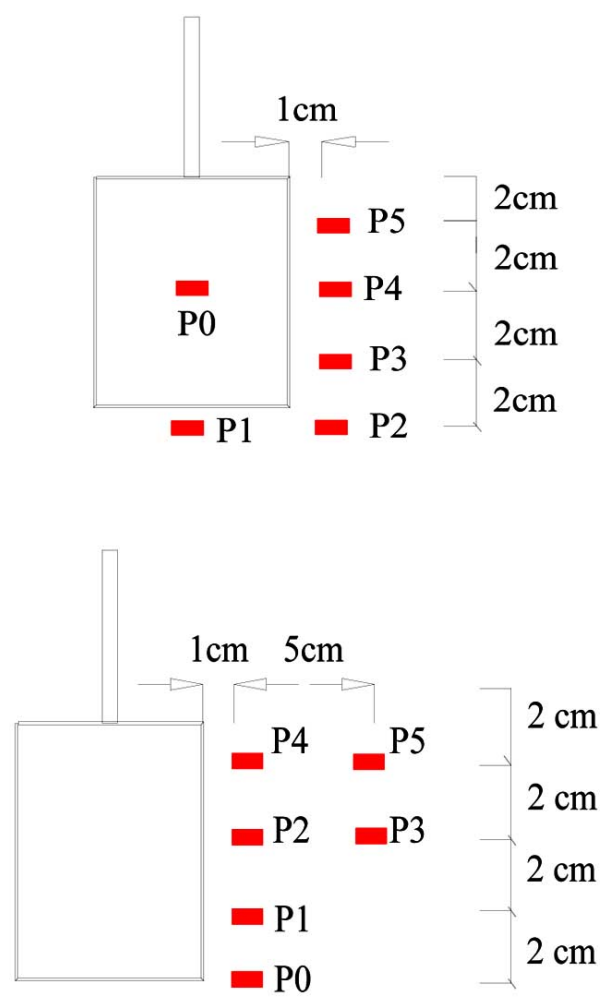

Fig. (4). Layout of pore pressure transducers.

- Measure the initial state of bucket and sand foundation (including the position of loading head, depth of water, bucket and sand surface). Turn on the loading system, measure the counter force and vertical displacement of bucket, pore pressure.

- Stop experiments when the vertical displacement of bucket does not develop anymore.

\section{EXPERIMENTAL RESULTS AND ANALYSIS}

\section{Vertical Static Bearing Capacity}

Experiments are carried out under different bucket's heights and different loading rates to obtain the static bearing capacity in calcareous sand layer. The values of the static bearing capacities may be a reference for choosing the loading amplitude in the dynamic loading experiments.

Fig. (3) shows the relations between the pull force and the displacements under different bucket's heights. Experimental results show. It is shown that with the increase of the bucket's height and the loading rate, the vertical static pull force increases. The reason is that with the increase of the loading rate, the suction force increases, which leads the increase of the pull force. The increase of the bucket's height increases the contacted area between the bucket and the sand layer, thus the pull force increases.

\section{Experiments Under Vertical Dynamic Loading}

The loading frequency is $0.15 \mathrm{~Hz}$ and the loading amplitude is $0.2 \mathrm{~cm}$ in the following depiction (but for noting specially)(Here the amplitude means half wave peak).

The model bucket used in experiments has a diameter of $10 \mathrm{~cm}$, a height of $7.5 \mathrm{~cm}$, a sidewall's thickness of $0.2 \mathrm{~cm}$ and a top cap's thickness of $1 \mathrm{~cm}$. For obtaining the characteristics of pore pressure distribution in horizontal and vertical directions, the layout of PPTs is shown in Fig. (4). The PPts are made in Druck co. in England.

\section{Deformation of the Sand Surface}

Experimental results show that there exists a limited effected zone for a given condition (Fig. 5). A circular effected zone with a diameter about $0.5 \mathrm{~cm}$ forms several cycles after loading applied. Outside the effected zone, sand layer settles a little. The effected zone expands gradually and the settlement increases under the loading. At last, the limited effected zone has a limited radius about two times the radius of bucket.

The phenomenon may be explained by the fact that under the vertical loading, the sand layer surrounding the bucket settles because of the consolidation by the dissipation of the excess pore pressure. The loading degrades with distance, which leads to the decrease of excess pore pressure with distance from the side wall of the bucket. For a given condition, the responses of sand layer become elastic at some distance away from the side wall of bucket.

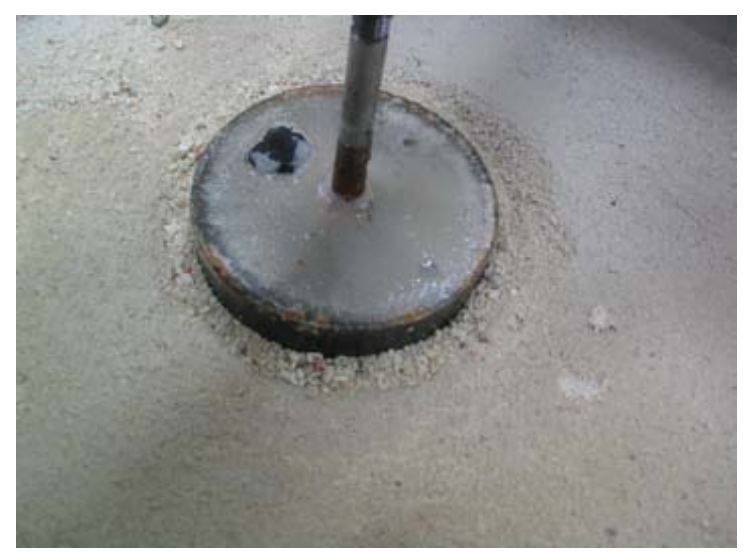

Fig. (5). A photo 60min after load.

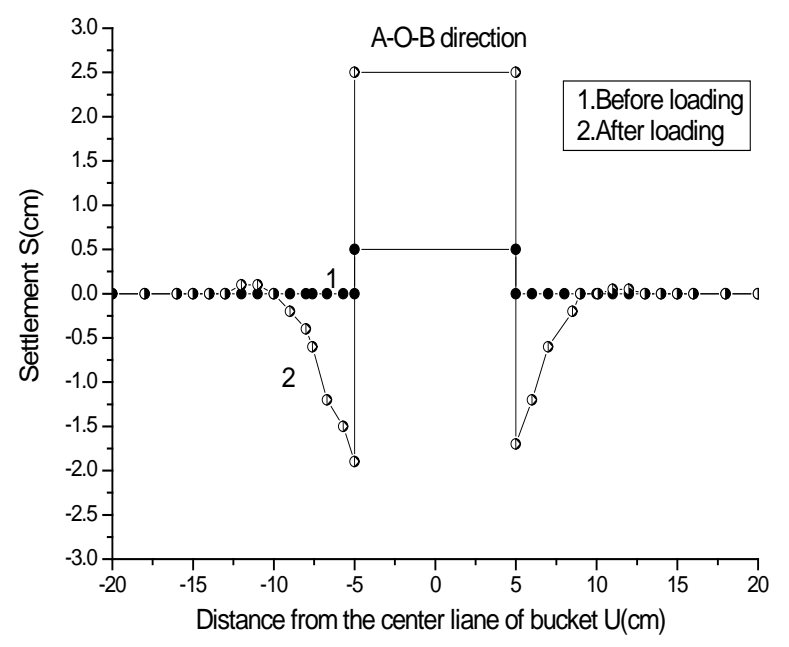

Fig. (6). The positions of bucket and soils surface after experiment. 

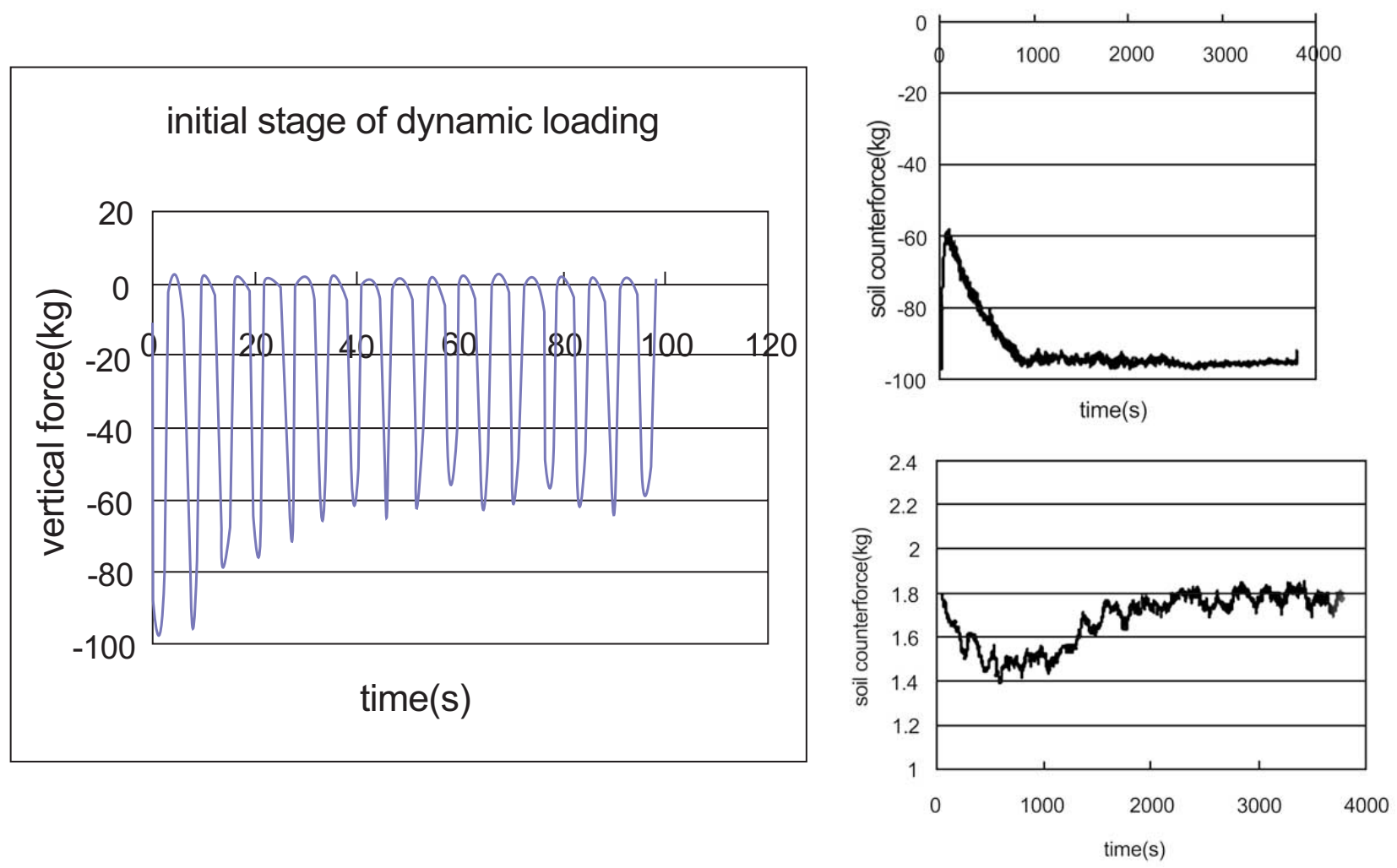

Fig. (7). (a) Counter force of soil layer initial stage (b) Maximum of pressing force (c) Maximum of pulling force.

\section{Development of the Counter Force}

Fig. (7) shows the development of the bucket's counter force. It is shown that the counter force upwards is less than that downwards. The reason is that under vertical loadings, the upwards counter force is consisted of the friction between the bucket's side wall and the sand layer and suction force, the downwards counter force is consisted of the side friction and the end resistance. The suction force is smaller than the end resistance because the permeability of the calcareous sand is big. The upwards counter force decreases at the first stage and then increases to a steady value.

Because the permeability of the calcareous sand is big, thus the excess pore pressure caused by vertical dynamic loading is small also. the decrease of the sand layer's strength is small. The strength of the sand layer increases with the drainage, thus the side friction and the end resistance increases.

\section{Changes of the Sand's Density}

The initial density is $1.26 \mathrm{~g} / \mathrm{cm}^{3}$, while the dry density inner the bucket increases a little after dynamic loading, the value is $1.288 \mathrm{~g} / \mathrm{cm}^{3}$ and the dry density below the bucket increases to $1.305 \mathrm{~g} / \mathrm{cm}^{3}$. The density besides the effected zone does not change. Because the dynamic loading causes the excess pore pressure increase, which leads to the decrease of the sand layer's strength and stiffness, thus the sand settles with drainage and the plastic deformation.

\section{Development of Excess Pore Pressure}

Fig. (8) shows the development of excess pore pressure with time surrounding the bucket. It is shown that the pore pressure increases at the first half an hour. Then the pore pressure becomes stable. The excess pore pressure increases more at the lower part because it drains slower. At the position $5.0 \mathrm{~cm}$ away from the side wall of the bucket, the excess pore pressure equals zero. In our experiments, the biggest liquefaction index (the ratio of the excess pore pressure to the initial effective stress) is only about 0.2 . The reason is the permeability is big and the grains are easy to break up.

\section{Effects of the Loading Amplitude}

In order to investigate the effects of loading amplitudes on the dynamic responses of the bucket and the sand layer, the experiments are carried out under the loading amplitudes of $0.2 \mathrm{~cm}$ and $0.5 \mathrm{~cm}$ (the corresponding frequency is $0.15 \mathrm{~Hz}$ ). Fig. 9(a) shows the settlements of the sand layer under different loading amplitudes. It is shown that the radius of effected zone increase from $3 \mathrm{~cm}$ to $5 \mathrm{~cm}$ while the amplitudes increase from $0.2 \mathrm{~cm}$ to $0.5 \mathrm{~cm}$. The maximum settlement is near the side wall of bucket. Outside the effected zone, the deformation of sand layer is zero.

\section{Effects of the Loading Frequency}

Fig. 9(b) shows the development of the sand layer's settlement under different loading frequencies. It is shown that the radius of the effected zone increase from $3 \mathrm{~cm}$ to $7 \mathrm{~cm}$ while the loading frequency increases from $0.1 \mathrm{~Hz}$ to $1 \mathrm{~Hz}$. Nevertheless, the settlement decreases with the increase of loading frequency. The reason is that the loading beard by sand layer increases with the increase of loading frequency, but the drainage decreases with the increase of the loading frequency. Thus, the loading may transfer more distance with the increase of loading frequency. 


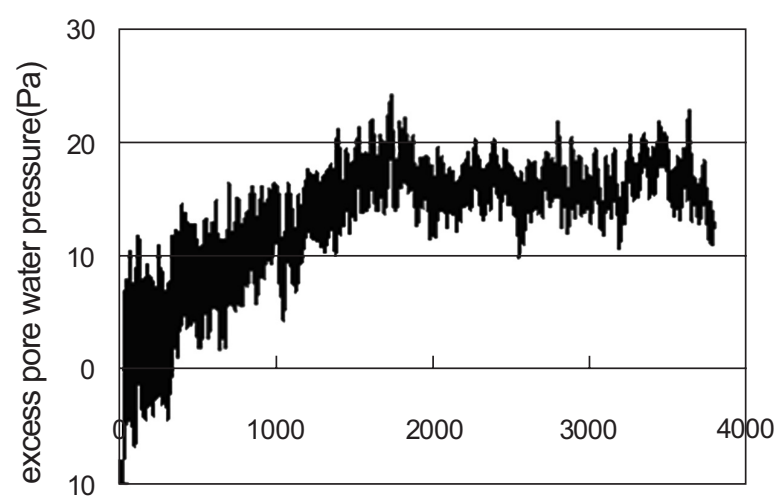

time(s)

(a) $\mathbf{P 4}$

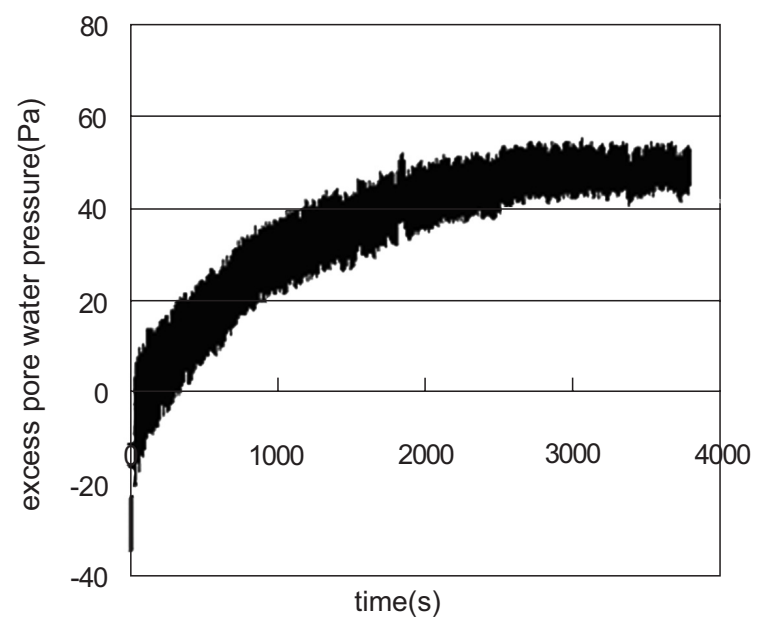

(b) P2

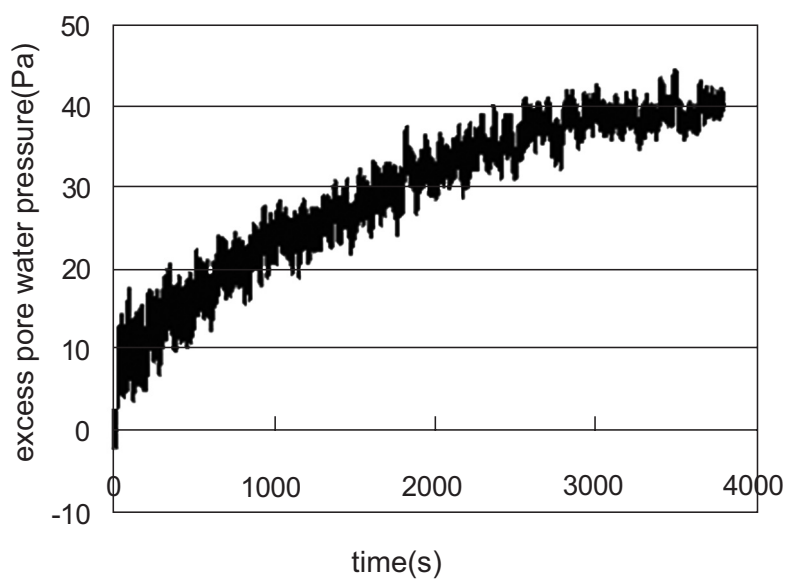

(c) P3

Fig. (8). Excess pore pressure at different depth.

\section{CONCLUSIONS}

Experiments on the vertical static bearing capacity of bucket foundations in calcareous sand have been carried out under different bucket's heights and loading rates. It is shown that the static vertical bearing capacities increase with the increase of loading rate and bucket's height.

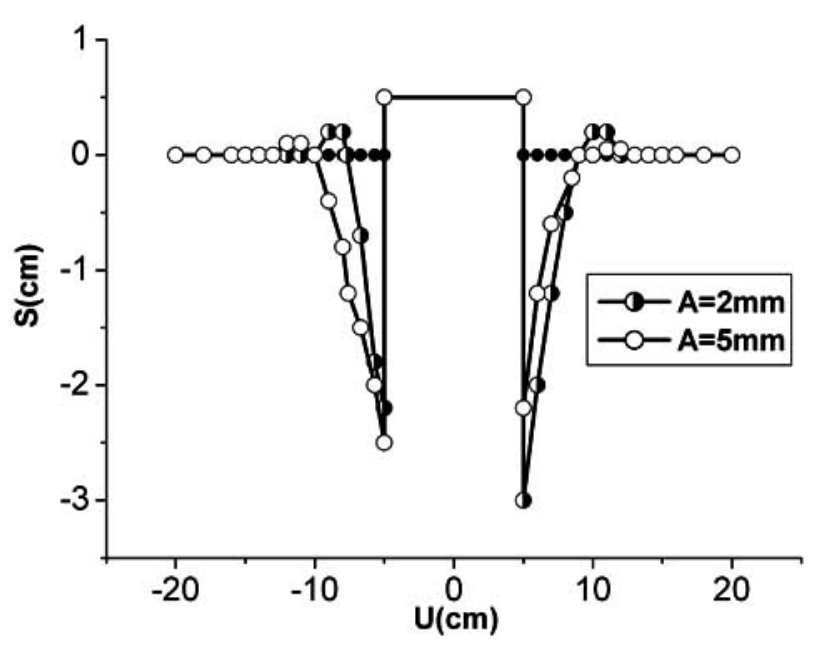

(a) Amplitude

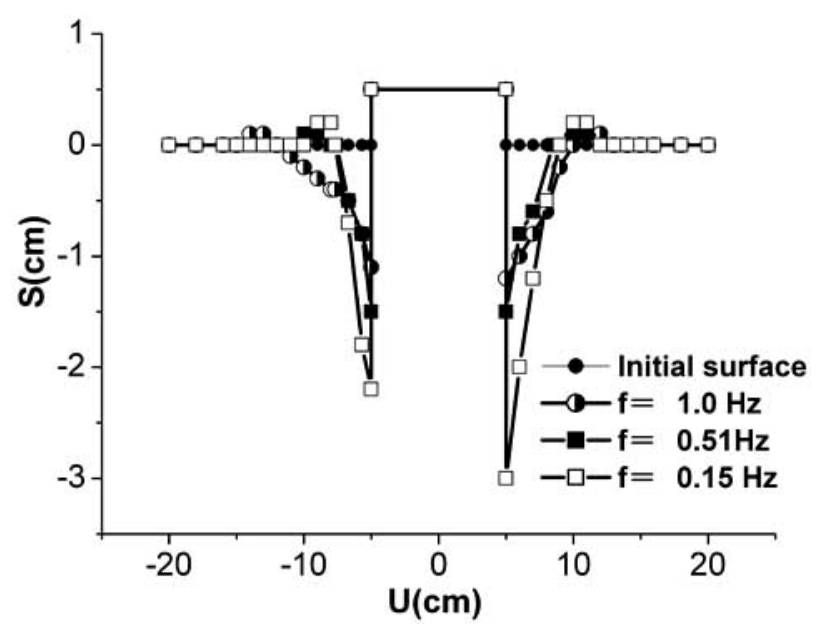

(b) Frequency

Fig. (9). The positions of bucket and soil surface after experiments.

The responses of bucket under vertical dynamic loading have been studied experimentally. The effects of some factors have been investigated. It is shown that there exists a limited effected zone under vertical dynamic loading. The effected zone has a diameter of one times of the height of bucket. During dynamic loading, fine grains flow to the surface of sand layer. The counter fore of the bucket first decreases and then increases to a steady value. The density surrounding the bucket increases after experiments. With the increase of loading amplitude and frequency, the responses become more and more obvious.

This paper is supported by National High Technology Research and Development Program of China (863) and National Natural Science Fund (No. 10772182) and Key Program of Chinese Academy of Sciences"KJCX2-YW-L02". Zhao Jing and Wang Ailan take part in all the experiments.

\section{REFERENCES}

[1] E.C. Clukey, M.J. Morrison, and J. Garnieret, "The response of suction caissons in normally consolidated clays to cyclic TLP load- 
ing conditions," In: Proc. Offshore Technol. Conf., Houston, OTC 7796, 1995, pp. 909-918.

[2] H.G.B. Allersma, F.J.A. Plenevaux, and J.F.P.C.M.E. Wintgens, "Simulation of suction pile installation in sand in a geocentrifuge," In: Proc. $7^{\text {th }}$ Int. Offshore Polar Eng. Conf. Honolulu, Hawaii: USA, vol. 1, 1997, pp. 761-765.

[3] H.G.B. Allersma, A.A. Kierstein, and D. Maes, "Centrifuge modeling on suction piles under cyclic and long term vertical loading," In: Proc. $10^{\text {th }}$ Int. Offshore Polar Eng. Conf., Seattle, USA, Int. Society of offshore and polar engineers, 2000, pp. 334-341.

[4] G.T. Housby, and A.M. Puzrin, "A thermomechanical frame-work for constitutive models for rate-independent dissipative materials," Int. J. Plasticity, vol. 16, no. 9, pp. 1017-1047, 2000.

[5] B.W. Byrne, G.T. Housby, C.M. Martin, and P.M. Fish, "Suction caisson foundations for offshore wind turbines," Wind Eng., vol. 26, no. 3, pp. 145-155, 2002.

[6] B.W. Byrne, and G.T. Houlsby, "Experimental investigations of the responses of suction caissons to transient combined loading," ASCE J. Geotech. Geoenviron. Eng., vol. 130, no. 3, pp. 240-253, 2004.

[7] K.H. Andersen, and H.P. Jostad, "Foundation design of skirted foundations and anchors in clay," In: Proc. Offshore Technol. Conf., Houston, Texas, OTC 10824, 1999, pp. 1-10.

[8] D. Senpere, and G.A. Auvergne, "Suction anchor piles-a proven alternative to driving or drilling," In: Proc. Offshore Technol. Conf., Houston, OTC 4206, 1982, pp. 483-493.

[9] W. Dyme and G.T. Houlsby, "Drained behavior of suction caisson on very dense sand," In: Proc. Offshore Technol. Conf., Houston, OTC10994, 1998, pp. 765-782.

[10] T.L. Tjelta, J Hermstad, and E. Andenaes, "The skirt piled gullfaks c platform installation," In: Proc. Offshore Technol. Conf., Houston, OTC 6473, 1990, pp. 453-462.

[11] A. Bye, C. Erbrich, B. Rognlien, and T.I. Tjelta, "Geotechnical design of bucket foundation," In: Proc. Offshore Technol. Conf., Houston, OTC 7793, 1995, pp. 869-883.

[12] X.B. Lu, Y.R. Wu, and B.T. Jiao, "Centrifugal experimental study of suction bucket foundations under dynamic loading," Acta Mech. Sin., vol. 23, pp. 689-698, 2007.

[13] G.T. Housby, and A.M. Puzrin, "A thermomechanical frame-work for constitutive models for rate-independent dissipative materials," Int. J. Plasticity, vol. 16, no. 9, pp. 1017-1047, 2000.
[14] J.R.C. De Mello, and C.D.S. Amaral, "Closed-Ended pile piles: testing and piling in calcareous sand," In: Proc. $21^{\text {th }}$ Ann. offsore Technol. Conf. Australia, Houston, 1989, pp. 341-352.

[15] J. Angemeer, E. Carlson, and J.H. Klick, "Techniques and results of offshore pile load testing in calcareous sand," In: Proc. $5^{\text {th }}$ Annu. Offshore Technol. Conf., Offshore Technol. Conf., Houston, Texas, OTC 1894, 1973, pp. 677-692.

[16] M.S. Khorshid, "Development of geotechnical experience on the North-West Shelf," Australian Geomech., vol. 19, pp. 11-21, 1990.

[17] M.F. Randolph, M.P. O'Neill, D.P. Stewart and C. Erbirch, "Performance of suction anchors in fine-grained calcareous soil," In: Proc. Offshore Technol. Conf., Houston, OTC 8831, 1998, pp. 521529.

[18] G.J. Dyson and M.F.Randolph, "Monotonic lateral loading of piles in calcareous sand," ASCE J. Geotech. Geoenviron. Eng., vol. 127, no. 4, pp. 346-352, 2001.

[19] H.R. Al-douri, and H. G. Poulos, "Static and direct shear tests on carbonate sands," Geotech. Test. J., vol. 121, no. 1, pp. 138-155, 1992.

[20] H.R. Al-douri, and H.G. Poulos, "Predicted and observerd cyclic performance of piles in calcareous sand," J. Geotech. Eng., vol. 121, no. 1, pp. 1-16, 1995.

[21] P.G. Waston and M.F. Randolph, "Vertical capacity of caisson foundations in calcareous sediments, "In: Proc. $7^{\text {th }}$ Int. Offshore Polar Eng. Conf., Honolulu: U.S.A, May 25-30, 1997, pp. 784-790.

[22] M.J. Cassidy, B.W. Byrne, and G.T. Houlsby "Modeling the behaviour of circular footings under combined loading on loose carbonate sand," Geotechnique, vol. 52, No. 10, pp. 705-712, 2002.

[23] M.J. Cassidy, D.W. Airey, and J.P. Carter, "Numerical modeling of circular footings subjected to monotonic inclined loading on uncemented and cemented calcareous sands," ASCE J. Geotech, Geoenviron. Eng., vol. 131, No. 1, pp. 52-63, 2005.

[24] X.F. Chu, Z.G. Li, and R. Wang, "The test research of anchor's uplift behavior in calcareous sand," Rock Soil Mech. vol. 23, no. 3, pp. 368-371, 2002 (in Chinese).

[25] H.G. Shan, and R. Wang, "Development of study on pile in calcareous sand," Rock Soil Mech., vol. 21, no. 3, pp. 299-308, 2000 (in Chinese)

(C) Lu et al.; Licensee Bentham Open.

This is an open access article licensed under the terms of the Creative Commons Attribution Non-Commercial License (http://creativecommons.org/licenses/by-nc/3.0/) which permits unrestricted, non-commercial use, distribution and reproduction in any medium, provided the work is properly cited. 